\title{
Crescimento do emprego industrial local no Brasil: o grau de especialização por intensidade tecnológica importa?
}

Growth of local industrial employment in Brazil: does the degree of specialization by technological intensity matter?

\author{
Eduardo Gonçalves (1) \\ Raphael de Freitas Saldanha (2) \\ Eduardo Almeida ${ }^{(3)}$ \\ André Suriane da Silva (4)
}

\author{
(1) Universidade Federal de Juiz de Fora \\ (2) Universidade Federal de Juiz de Fora \\ ${ }^{(3)}$ Universidade Federal de Juiz de Fora \\ (4) Universidade Federal de Juiz de Fora
}

\begin{abstract}
The aim of this paper is to revisit the debate on the degree of specialization and industrial diversification and the growth of local manufacturing employment in Brazil. A matrix of sectoral spillovers is built in which it is verified whether sectors, grouped by technological intensity, influence the performance of disaggregated manufacturing groups. Spatial data panel techniques are used to control non-observed local effects and possible spatial dependence over the period 1995-2014. The results show that specializations in low-technology manufacturing groups create stimulus for several other manufacturing groups regardless of the level of technological intensity. The spillovers coming from high technology manufacturing industries are less frequent, though they also occur depending on the industrial manufacturing group considered. In general, sectors of higher and lower technological intensity flourish with the presence of MAR externalities. We conclude that the diversification/specialization debate can vary considerably, requiring specific industrial and regional policies by manufacturing industries.
\end{abstract}

\section{Keywords}

specialization; diversification; industrial technological intensity; inter-sectoral and spatial spillovers; Brazil.

JEL Codes R11; R12; O10.

\section{Resumo}

O objetivo desse artigo é revisitar o debate sobre o grau de especialização e de diversificação industrial e o crescimento do emprego industrial local no Brasil. Por meio de uma matriz de transbordamentos setoriais, o artigo verifica se setores, agrupados por intensidade tecnológica, influenciam o desempenho de grupos industriais desagregados. Utilizam-se técnicas de painel de dados espaciais para controlar efeitos municipais não observados e possivel dependência espacial no periodo 1995 2014. Os principais resultados revelam que especializações em grupos setoriais de baixa tecnologia geram transbordamentos para diversos outros grupos industriais, independentemente do nivel de intensidade tecnológica. Os estímulos provenientes de setores de alta tecnologia são menos frequentes, embora também ocorram, dependendo do grupo industrial considerado. Em geral, setores de maior e menor intensidade tecnológica florescem com a presença de externalidades do tipo MAR. Conclui-se que o debate diversificação/especialização pode variar consideravelmente, o que requer políticas industriais e regionais específicas por setores industriais.

\section{Palavras-chave}

especialização; diversificação; intensidade tecnológica industrial; transbordamentos intersetoriais e espaciais; Brasil.

Códigos JEL R11; R12; O10. 


\section{Introdução}

As razões que levam algumas localidades a se desenvolverem mais que outras é um tema recorrente na literatura. $O$ sucesso de algumas cidades pode estar relacionado à composição de sua estrutura econômica, à escala urbana ou a fatores externos às cidades. A estrutura econômica de uma cidade pode ser mais ou menos diversificada e ao mesmo tempo mais ou menos especializada em setores específicos. Aliadas à escala urbana, características da composição da estrutura econômica podem ocasionar desenvolvimento por gerarem externalidades.

Duas principais teorias discutem os efeitos de externalidades sobre o crescimento regional. A primeira é a de Marshall-Arrow-Romer, conhecida por externalidades MAR (Glaeser et al., 1992), que aponta as economias de localização como o motor do crescimento. As firmas aglomeradas poderiam se beneficiar de um mercado de trabalho concentrado, compartilhamento de insumos e informações técnicas, o que, consequentemente, resultaria na minimização de custos de produção e inovação. Assim, as externalidades do tipo MAR apontariam paras as vantagens advindas da especialização setorial.

A teoria Marshalliana (Marshall, 1982) serviu de inspiração para um segundo tipo de teoria de aglomeração: os clusters de Porter (1990). Os clusters possuem vantagens nos custos de informação e transação, complementaridades e incentivos, assim como em bens públicos que resultam de investimentos públicos e privados. Ainda segundo o autor, os clusters melhoram a produtividade pela facilidade de acesso aos insumos e informações, facilitando complementaridades entre os participantes e diminuindo as barreiras para a inovação e para a formação de novos negócios. Esses argumentos podem ser justificados pela importância da distância geográfica na viabilização das interações entre os agentes, os quais se adéquam à dimensão geográfica das externalidades, segundo Rosenthal e Strange (2004).

Em outro extremo, tem-se a teoria de Jacobs (1969), segundo a qual as economias de diversificação impulsionam o crescimento e a prosperidade de uma região. Para essa teoria, a existência de diversos tipos de serviços em grandes aglomerações facilitaria a transmissão de conhecimentos. Dessa forma, a diversificação é considerada como motor da transmissão de ideias e tecnologia, ou seja, do crescimento local. 
A partir dos trabalhos de Glaeser et al. (1992) e Henderson, Kuncoro e Turner (1995), as tentativas de mensuração do impacto das externalidades estáticas e/ou dinâmicas sobre o crescimento local proliferaram. Há uma diversidade de abordagens metodológicas para o tema. Apoiado na metodologia proposta por Forni e Paba (2002), o presente artigo objetiva construir uma matriz de transbordamentos setoriais, com base em evidências indiretas, para os setores industriais brasileiros entre os anos de 1995 e 2010, por municípios. A partir dessa matriz é possível verificar se a especialização num determinado setor influência a taxa de crescimento de outro setor, assumindo-se que um setor gera externalidades que impactam a taxa de crescimento de outros. Além disso, estende-se o trabalho de Forni e Paba (2002) no sentido de se considerar os transbordamentos espaciais, que podem ser importantes, como mostrado nos argumentos de Porter (1990) sobre a formação de clusters espaciais e de Rosenthal e Strange (2004) sobre a dimensão geográfica das externalidades.

No Brasil, há trabalhos que buscam evidências da relação entre economias de aglomeração e salários por trabalhadores na indústria (Galinari et al., 2007; Catela, Gonçalves e Porcile, 2010; Dalberto e Staduto, 2013). Por outro lado, são poucos os textos que exploram a relação entre crescimento local de empregos e externalidades derivadas de economias de aglomeração (diversificação e especialização). Fochezatto e Valentini (2010) estudaram o caso do Rio Grande do Sul, escolhendo alguns setores para avaliar a relação entre a estrutura produtiva e o crescimento de empregos. Badia e Figueirêdo (2007) estimam um painel para 12 setores selecionados da indústria brasileira entre 1985 e 2000. Os autores afirmam que ambos os tipos de externalidades são importantes, com impacto dos graus de especializações e de diversificação da indústria observados no passado sobre o crescimento local, sendo variável o timing desses efeitos por setor. Silva e Silveira Neto (2007) regridem o crescimento do emprego nos estados no período 20021994 contra proxies de externalidades de especialização e diversificação, além de outras variáveis de controle, medidas no início do período.

O presente artigo propõe revisitar o tema de externalidades de especialização e diversificação, refinando o debate ao incorporar o impacto de especializações setoriais por nível de intensidade tecnológica sobre o emprego local. Propõe-se uma matriz de transbordamentos intersetoriais e intrassetoriais positivos e negativos para a economia brasileira. Além desse ponto, o artigo avança na literatura brasileira ao propor uma abordagem 
que considera não somente todos os setores da indústria geral brasileira, mas também todos os municípios do Brasil, incorporando amplo período de análise pós-estabilização monetária (1995-2014). Aplica-se a metodologia de painel de dados espaciais, que permite controlar para os efeitos não observados municipais, além de incorporar a dependência espacial no modelo com rotina de programação construída no software $\mathrm{R}$ e disponibilizada pelos autores sob requisição.

Além desta introdução, este artigo apresenta uma seção de revisão de literatura. A terceira seção apresenta, de forma resumida, a base de dados e a especificação empírica. A quarta traz a metodologia necessária para a análise ora proposta. A quinta apresenta os resultados e, por fim, seguem-se algumas considerações finais.

\section{0 papel das externalidades sobre o crescimento do emprego local: uma revisão da literatura}

Economias externas surgem quando o tamanho da escala urbana afeta a produtividade dos agentes, podendo ocorrer sob três dimensões: industrial, geográfica e temporal (Rosenthal; Strange, 2004). Na dimensão industrial, economias externas surgem quando a concentração de atividades econômicas no espaço, decorrentes do tamanho da cidade, geram reduções de custos para os agentes aí localizados (economias de urbanização). Se a concentração de empresas se refere ao mesmo setor, economias de localização surgem. Segundo Henderson, Kuncoro e Turner (1995), economias de localização e urbanização são exemplos de economias de aglomeração estáticas em que os agentes se beneficiam de transbordamentos de informações imediatas.

A dimensão geográfica reflete-se na ideia de que as economias de aglomeração se atenuam com a distância. A proximidade física entre os agentes dentro da cidade é vantajosa e determinante para a própria existência das cidades. Se os agentes estão fisicamente mais próximos, o potencial para interação é maior (Rosenthal; Strange, 2004).

A dimensão temporal se expressa na ideia de que o impacto das interações entre os agentes no passado pode se repercutir sobre a produtividade futura, pelo fato, entre outras razões, de o aprendizado ocorrer gradualmente. Esse é o aspecto dinâmico das economias de aglomeração, 
que as diferenciam das economias de aglomeração estáticas. Nesse caso, a acumulação de informações no decorrer do tempo afeta a produtividade corrente e, consequentemente, o nível de emprego (Rosenthal; Strange, 2004; Henderson; Kuncoro; Turner, 1995). Como nas externalidades estáticas, as dinâmicas também poderiam ser classificadas em economias de localização e de urbanização. As primeiras seriam resultantes do acúmulo de conhecimento derivado da contínua comunicação de firmas do mesmo setor e poderiam ser denominadas de externalidades do tipo Marshall-Arrow-Romer (MAR) por causa das contribuições seminais desses autores (Glaeser et al., 1992; Henderson; Kuncoro; Turner, 1995). As segundas são resultantes do acúmulo do conhecimento associado à diversidade histórica, como descrito originalmente por Jacobs (1969).

Embora as implicações sobre as cidades sejam similares, comparando-se as externalidades estáticas e dinâmicas, as externalidades dinâmicas são mais úteis para explicar o desenvolvimento industrial urbano ao longo do tempo. Glaeser et al. (1992) utilizam a teoria das externalidades dinâmicas para explicar o desenvolvimento das inovações no interior dos centros urbanos. Cidades facilitam o fluxo de ideias de pessoas para pessoas em razão da aglomeração, o que remete à ideia de a distância física ser fator importante na transmissão do conhecimento tácito. Logo, apesar dos custos da aglomeração (aluguéis e custos de congestionamento diversos), as cidades são vistas como lócus de crescimento, inovação e prosperidade econômica (Romer, 1986; Lucas, 1988).

Embora a literatura desenvolva trabalhos mostrando oposição entre as economias de localização e urbanização, em particular devido aos tratamentos ao tema dados por Marshall (1982) e Jacobs (1969), Rosenthal e Strange (2004) argumentam que o próprio Marshall soube reconhecer o valor da diversidade urbana, em termos de complementaridade e redução de risco em face de reduções de demanda. Duranton e Puga (2001) apresentam argumentos teóricos segundo os quais as externalidades de diversificação seriam mais importantes para novos setores industriais, de rápido crescimento; ao passo que, para setores maduros, maior importância teriam as externalidades de especialização, por diminuírem os custos de produção.

Os trabalhos empíricos que tentam medir os efeitos das economias de aglomeração (estáticas ou dinâmicas) sobre o crescimento urbano se baseiam na estimação de uma função de produção que vincula medidas 
de produto de uma firma às dimensões das economias de aglomeração mencionadas anteriormente. Entretanto, tendo em vista os desafios econométricos associados a essa estimação, como necessidade de vários tipos de medidas (terra, capital, trabalho e outros insumos), vieses de variáveis omitidas e questões de simultaneidade, as tentativas de medir o efeito das economias de aglomeração se baseiam, muitas vezes, em estratégias indiretas, com base em medidas de emprego, de nascimento de novas empresas, salários e aluguéis.

Beaudry e Schiffauerova (2009) afirmam que os dados de emprego são mais comumente usados como variável dependente dos estudos sobre externalidades do tipo MAR e Jacobs. Em geral, há resultados mais frequentes para as externalidades de Jacobs, embora também existam trabalhos que encontrem resultados favoráveis a ambos os tipos de externalidades.

Entre os trabalhos mais importantes que usam dados de emprego, situam-se os de Glaeser et al. (1992), Henderson, Kuncoro e Turner (1995), Forni e Paba (2002), Paci e Usai (2006) e Lu et al. (2013). Glaeser et al. (1992) afirmam que a especialização prejudica o crescimento urbano, ao passo que a competição local e a diversidade o estimulam. Henderson, Kuncoro e Turner (1995) consideram o nível tecnológico setorial separadamente e incluem outros fatores responsáveis pelo crescimento industrial, como condições de demanda do produto e mercado de trabalho local. Os resultados sugerem que o crescimento do emprego em indústrias tradicionais é maior em cidades que tinham maior concentração desses setores no passado, como estabelecido por Marshall-Arrow-Romer. Por outro lado, a predominância de externalidades dinâmicas de diversificação é relevante para a atração e desenvolvimento de indústrias de alta tecnologia, favorecendo a tese de Jacobs.

Com base na experiência da França, Combes (2000a; 2000b) faz uma crítica metodológica a uma parte dessa literatura, em particular Glaeser et al. (1992) e Henderson, Kuncoro e Turner (1995). Segundo o autor, os resultados favoráveis à especialização seriam devidos à inclusão do emprego total do setor como variável de controle, que superestimaria as chances de encontrar resultados significativos para as externalidades do tipo MAR. Para a França, Combes (2000a) não encontra importância das variáveis de especialização para o crescimento do emprego industrial, como Henderson, Kuncoro e Turner (1995) encontraram para as cidades americanas. Segundo o autor, a variável de controle ideal seria o emprego total da cidade, que 
controla todos os efeitos possíveis relacionados ao tamanho da cidade. Tais efeitos podem ser positivos, decorrentes de demanda local ou de provisão de bens públicos locais, ou negativos, como efeitos de congestão pelo uso do solo ou derivados de redes de transportes. Após controlar o tamanho da cidade, a concentração relativa do setor na cidade passa a captar as externalidades do tipo MAR, representando o efeito real do aumento do emprego setorial local sobre o crescimento total do emprego na cidade. Combes, Magnac e Robin (2004) também usam o emprego total da área para controlar as externalidades de urbanização globais, que seriam relacionadas ao tamanho do mercado local e não à composição industrial da área.

Combes (2000b) incorpora o setor serviços e usa modelos Tobit, além de substituir a variável total do emprego setorial local por emprego total da cidade como regressor. $O$ autor usa todas as unidades geográficas, ao contrário de Glaeser et al. (1992), para evitar viés de seleção e faz regressões globais empilhando os dados de todos os setores, além de realizar regressões por setor de atividade. Os resultados mostraram que há pouca influência das economias de localização sobre indústria e serviços. $\mathrm{O}$ autor explica o resultado pela teoria do ciclo de vida do produto, em que, nas fases iniciais, há surgimento de produtos e, especialmente, serviços em poucos locais. Posteriormente, há uma dispersão de tais produtos e serviços no espaço. Para setores tradicionais, que experimentavam decréscimo no emprego no nível nacional, um alto grau de especialização implicaria menor flexibilidade, pior adaptabilidade de produtos, tecnologias e infraestruturas da cidade quando o setor declina. Em relação às economias de urbanização, ocorrem efeitos positivos nas regressões globais para os serviços, embora na indústria os resultados mostrem influência negativa. Houve apenas influência positiva da diversidade local sobre o crescimento da indústria de computadores, mostrando que as economias de aglomeração são sensíveis no nível tecnológico dos setores econômicos.

Forni e Paba (2002) inovam por tentar construir uma matriz de transbordamentos setoriais, ainda que baseada em evidências indiretas, a partir do índice de especialização para localidades italianas. A vantagem dessa abordagem está em evitar a contraposição das externalidades interindustriais ou intraindustriais, como se fossem propriedades excludentes do território. De fato, há uma série de trabalhos que apontam para o fato de as externalidades de diversificação e de especialização poderem coexistir e não serem mutuamente excludentes (Koo, 2005; Paci; Usai, 2000). Nesse sen- 
tido, diferentes territórios podem conter inúmeras combinações possíveis entre graus de especialização de um setor e de diversidade do território em que ele se encontra localizado. Por outro lado, em termos metodológicos, o trabalho de Forni e Paba (2002) também pode estar sujeito à crítica de Combes (2000a), por incluir o emprego local setorial como regressor, o que pode superestimar a importância dos indicadores de especialização. Além disso, a especificação econométrica dos autores não inclui alguns fatores locais importantes para explicar crescimento local, como o capital humano, além de o trabalho não utilizar métodos econométricos que lidem com autocorrelação espacial, tendo em vista que o desempenho das cidades pode ser correlacionado espacialmente.

Os resultados de Forni e Paba (2002) indicam que: a) tanto a especialização quanto a diversidade importam para o crescimento local, embora cada setor precise de sua própria variedade; $b$ ) os transbordamentos guardam estreita conexão com as relações de insumo-produto, seguindo, em muitos casos, caminhos upstream, originando-se em produtores de bens finais e se dirigindo a fornecedores na origem da cadeia produtiva; c) a importância do transbordamento setorial não depende da intensidade tecnológica, ocorrendo tanto em setores de baixa como de alta tecnologia; d) produtos do metal e setores produtores de máquinas têm ligações dinâmicas com quase todos os outros setores, mas são principalmente recebedores de transbordamentos.

Paci e Usai (2006) argumentam que regressões de crescimento de emprego são capazes de gerar interessante informação da relação entre condições locais e emprego, mas não entre condições locais e crescimento de produtividade. Ao contrário de Forni e Paba (2002), esses autores consideram a possibilidade de autocorrelação espacial nos dados. Os autores usam as medidas de externalidades de Marshall, Jacobs e grau de competição, além de outras características do sistema local de trabalho. Os resultados apontam coeficientes negativos para as externalidades de especialização, possivelmente devido a crises que desorganizaram o sistema produtivo local. As externalidades de diversificação foram positivamente relacionadas ao crescimento local da economia.

Lu et al. (2013), para a China, encontraram resultados favoráveis à especialização, embora a diversidade não tenha efeito significativo. Uma possível explicação apontada é o fato de a economia chinesa ser caracterizada predominantemente por setores industriais maduros no período estudado. 
Para o Brasil, há poucos trabalhos que relacionam o crescimento de empregos urbanos à estrutura econômica local, considerando externalidades do tipo MAR e Jacobs. Encontram-se três grupos de trabalhos, usuários de dados de emprego, salários e inovação, respectivamente. Entre os primeiros, situam-se, por exemplo, Fochezatto e Valentini (2010), Silva e Silveira Neto (2007) e Badia e Figueirêdo (2007). Entre os segundos, citam-se Galinari et al. (2007), Catela, Gonçalves e Porcile (2010) e Dalberto e Staduto (2013). No terceiro grupo, situam-se Gonçalves e Almeida (2009) e Montenegro, Gonçalves e Almeida (2011).

Para o primeiro grupo, há evidências de que setores industriais do Rio Grande do Sul estariam se beneficiando de externalidades decorrentes da estrutura produtiva local, como as de especialização (MAR), de diversificação urbana (Jacobs) e de competição (Porter, 1990), segundo Fochezatto e Valentini (2010). Badia e Figueirêdo (2007) verificaram que ambos os tipos de externalidades (MAR e Jacobs) são relevantes para os setores selecionados. Silva e Silveira Neto (2007), porém, encontram relação positiva apenas entre a diversidade industrial e o crescimento do emprego estadual no Brasil.

No grupo de trabalhos que usam salários por trabalhador como variável dependente, Galinari et al. (2007) e Dalberto e Staduto (2013) têm propostas similares. Verificou-se que as economias de aglomeração, especialmente as economias de diversificação/urbanização, são importantes. Em média, constatou-se que cidades com base industrial diversificada possuem salários mais elevados. Catela, Gonçalves e Porcile (2010) inovam metodologicamente ao usarem regressões de misturas finitas que permitiram encontrar resultados diferentes para dois grupos de municípios. Para um grupo de municípios, caracterizado por menores níveis de salários médios, não há importância das economias de especialização (externalidades MAR), embora haja relevância das economias de urbanização. Para o grupo com maiores níveis de salários médios, que incluíam os municípios sedes de grandes áreas metropolitanas brasileiras, como São Paulo, Rio de Janeiro, Belo Horizonte, Porto Alegre e Curitiba, as economias de especialização eram altamente significativas, com fracos efeitos de economias de urbanização sobre a variável dependente.

Em relação aos trabalhos que focam inovação, Gonçalves e Almeida (2009) constataram que a diversidade industrial, captada pelo indicador de Hirschman-Herfindhal, afeta positivamente a inovação regional. Mon- 
tenegro, Gonçalves e Almeida (2011) focaram o Estado de São Paulo e constaram que as medidas de especialização e diversificação fomentavam simultaneamente a inovação.

Com base nas revisões de literatura aqui comentadas, pode-se concluir que a metodologia e a estratégia empírica explicitadas a seguir podem ainda contribuir para o tema no Brasil, principalmente no período recente de atividade produtiva brasileira.

\section{Estratégia empírica}

A metodologia empregada neste artigo é baseada na proposta de Forni e Paba (2002). A diferença metodológica reside no fato de que, em vez de uma cross-section de municípios apenas, é usado aqui um painel de dados espaciais, em que a dimensão de corte transversal compreende os municípios, e a dimensão temporal abrange todos os anos compreendidos no período de 1995 a 2014. Incluem-se métodos de controle de efeitos não observados e de dependência espacial. Este estudo segue a sugestão metodológica de uso de painel de dados, porque, segundo Henderson (1997), tais métodos enfrentam a maior parte dos problemas desses estudos mencionados na seção 2, ao modelarem a dinâmica de curto prazo do emprego local e o impacto da estrutura econômica local. Ademais, com um painel de dados espaciais é possível ainda levar em conta a dependência espacial.

Com isso, realizam-se regressões econométricas que procuram relacionar o desempenho de setores industriais por municípios brasileiros a medidas de especialização, além de outras variáveis de controle. As regressões são realizadas para cada um dos setores a 3 dígitos, tendo como número de observações a soma da quantidade de municípios brasileiros com informações disponíveis para cada um dos anos do período analisado. O modelo empírico-econométrico elaborado para capturar os transbordamentos setoriais e espaciais entre os segmentos industriais seguiu os seguintes procedimentos (cuja descrição das variáveis está no Quadro 1):

a) Primeiramente, foram estimados os modelos em painel com controle para efeitos fixos e aleatórios, conforme Eq. 1.

$$
\begin{aligned}
& \Delta l_{i h t}=\alpha_{i}+\beta_{1} \Delta \mathrm{n}_{i t}+\beta_{2} E_{i t}+\beta_{3} C_{i h t}+\beta_{4} C H_{i t}+\beta_{5} h h i_{i t}+\gamma_{1} p v 1_{i t}+\ldots+ \\
& +\gamma_{5} p v 5_{i t}+\varepsilon_{i t}
\end{aligned}
$$


b) O segundo passo consistiu em testar qual das abordagens aplicadas no primeiro passo foi mais adequada usando o teste Hausman.

c) Definido o modelo mais adequado entre efeitos fixos e aleatórios, o terceiro passo foi testar a dependência espacial utilizando o I de Moran para matrizes de K-vizinhos de 1 até 20.

d) Se ao menos um I de Moran foi significante para o modelo, foi estimado o modelo autorregressivo espacial (Spatial Autoregressive Model - SAR) em painel como segue para a matriz K-vizinhos com maior $I$ de Moran significante, conforme Eq. 2.

$$
\begin{aligned}
& \Delta l_{i h t}=\alpha_{i}+\rho W \Delta l_{i h t}+\beta_{1} \Delta \mathrm{n}_{i t}+\beta_{2} E_{i t}+\beta_{3} C_{i h t}+\beta_{4} C H_{i t}+\beta_{5} h h i_{i t}+ \\
& +\gamma_{1} p v 1_{i t}+\ldots+\gamma_{5} p v 5_{i t}+\varepsilon_{i t}
\end{aligned}
$$

e) Se ao menos um $I$ de Moran foi significante, mas com $\rho$ estimado pelo modelo SAR foi insignificante foi então estimado o modelo de erro espacial (Spatial Error Model - SEM), conforme a Eq. 3.

$$
\begin{aligned}
& \Delta l_{i h t}=\alpha_{i}+\beta_{1} \Delta \mathrm{n}_{i t}+\beta_{2} E_{i t}+\beta_{3} C_{i h t}+\beta_{4} C H_{i t}+\beta_{5} h h i_{i t}+\gamma_{1} p v 1_{i t}+\ldots+ \\
& +\gamma_{5} p v 5_{i t}+\xi_{i t} \xi_{i t}=\lambda W \xi_{i t}+\varepsilon_{i t}
\end{aligned}
$$

f) Se nenhum I de Moran foi significante, foram considerados os resultados dos passos 1 e 2 .

\section{Quadro 1 Descrição das variáveis}

\begin{tabular}{l|l}
\hline Variável & Descrição \\
\hline$\Delta l_{i h t}$ & $\begin{array}{l}\text { A variável dependente é a variação do emprego setorial a 3 dígitos Classificação } \\
\text { Nacional de Atividades Econômicas (CNAE) do município, os subscritos i, h e t indicam, } \\
\text { respectivamente, município, setor (3 dígitos) e o período de tempo; }\end{array}$ \\
\hline$\alpha_{i}$ & $\begin{array}{l}\text { Efeitos não observados, que podem assumir a forma de efeitos fixos ou efeitos aleató- } \\
\text { rios*; }\end{array}$ \\
\hline$W \Delta I_{i h t}$ & $\begin{array}{l}\text { Defasagem espacial da variável dependente que procura verificar a existência de trans- } \\
\text { bordamentos espaciais do crescimento do emprego urbano. Espera-se sinal positivo } \\
\text { para essa variável, partindo-se da premissa de que o crescimento econômico ocorre } \\
\text { sobre uma base territorial maior que a local; }\end{array}$ \\
\hline$\Delta n_{i t}$ & $\begin{array}{l}\text { Logaritmo da mudança do emprego total da área que busca controlar a variação do } \\
\text { emprego total do município, sendo uma variável usada por Forni e Paba (2002); }\end{array}$ \\
\hline
\end{tabular}


Quadro 1 (continuação)

\begin{tabular}{|c|c|}
\hline Variável & Descrição \\
\hline$E_{i t}$ & $\begin{array}{l}\text { Quantidade total de empregados do município, incluindo emprego não industrial, que } \\
\text { verifica a existência de externalidades urbanas que podem ser positivas, por causa de } \\
\text { efeito de demanda local ou provisão local de bens públicos, ou negativas, devido aos } \\
\text { efeitos de congestão urbana; }\end{array}$ \\
\hline$C_{\text {iht }}$ & $\begin{array}{l}\text { Número de estabelecimentos por empregados. Visa medir a competição local do setor, } \\
\text { podendo ser positiva, ao se esperar que menores firmas induzam crescimento, ou nega- } \\
\text { tiva, se grandes firmas são mais propensas a promover o crescimento setorial local; }\end{array}$ \\
\hline $\mathrm{CH}_{\text {it }}$ & $\begin{array}{l}\text { Variável representativa de capital humano, proporção de trabalhadores com nível } \\
\text { superior, sobre o emprego total, em cada município i, que possui sinal esperado positivo, } \\
\text { tendo em vista que pessoas mais educadas são mais capazes de criar e implementar } \\
\text { novos conhecimentos, o que gera crescimento local; }\end{array}$ \\
\hline$h h i_{i t}$ & $\begin{array}{l}\text { Índice de diversificação setorial (Herfindahl-Hirschman Index), calculado para } 64 \text { setores } \\
\text { a } 2 \text { dígitos CNAE, incluindo os não industriais (divisões CNAE, IBGE). Varia entre } 0 \text { (mais } \\
\text { diversificado) a } 1 \text { (mais especializado) por município; }\end{array}$ \\
\hline$p v X_{-i t}$ & $\begin{array}{l}\text { Medida do grau de especialização setorial, definida como soma da proporção do } \\
\text { emprego total do município no setor a } 2 \text { dígitos CNAE agregados segundo a intensidade } \\
\text { tecnológica (extrativa, baixa, média-baixa, média-alta e alta). Varia entre } 0 \text { a } 1 . \\
\text { São variáveis de interesse deste estudo, que podem ser negativas ou positivas, depen- } \\
\text { dendo da natureza da externalidade tecnológica. } \\
p v 1_{i t} \text { Setores de } 10 \text { até } 14 \text { somados (Ind. extrativas - baixa tecnologia); } \\
p v 2_{\text {it }} \text { Setores de } 15 \text { até } 22,36 \text { e } 37 \text { somados (baixa tecnologia); } \\
p v 3_{i t} \text { Setores } 23,25,26,27,28 \text { e subsetor } 351 \text { somados (média-baixa tecnologia); } \\
\left.p v 4_{\text {itt }} \text { Setores } 24 \text { (exceto } 245\right), 29,31,34,35 \text { (exceto } 351 \text { ) somados (média-alta tecnologia); } \\
p v 5_{i t} \text { Setores } 30,32,33 \text { e subsetores } 245 \text { e } 353 \text { somados (alta tecnologia). }\end{array}$ \\
\hline$W \xi_{\text {it }}$ & Defasagem espacial do termo de erro; \\
\hline$\varepsilon_{i t}$ & Termo de erro aleatório bem comportado, com média zero e variância constante. \\
\hline
\end{tabular}

Notas:* Se forem efeitos aleatórios, o termo ai será um dos componentes do termo de erro, fazendo com que este seja especificado do seguinte modo: $\xi_{\mathrm{it}}=\alpha_{\mathrm{i}}+\lambda \mathrm{W} \xi_{\mathrm{it}}+\varepsilon_{\mathrm{it}}$ no caso do modelo SEM.

Foram analisados inicialmente 109 setores a 3 dígitos $(h=1, \ldots, 109)$, sendo, cada um, analisado por meio de um exercício econométrico independente. Os setores são descritos no Quadro A2 (Apêndice). Nessa regressão inicial, o número de regressores totaliza 11, pois são incluídas as variáveis descritas nos itens 2 a 6, além das cinco medidas de especialização setorial (dos setores a 2 dígitos, Quadro A1 (Apêndice). $\bigcirc$ número de observações por regressão é variável porque muitos setores estavam ausentes ou no início (1995) ou no fim do período (2014). ${ }^{1}$ Nos casos de emprego setorial igual 1 Este trabalho pressupõe que os dados faltantes estão distribuídos aleatoriamente, não engendrando viés de seleção nem autocorrelação espacial. A matriz de correlação entre as variá- 
a zero em 1995 ou 2014, o logaritmo do emprego foi estabelecido como zero. Além disso, foram eliminados, para cada setor, todos os municípios com emprego zero tanto em 1995 quanto em 2010. Também foram excluídos da análise setores que tiveram menos de 30 observações para um determinado ano (Ver Apêndice). Assim, o número total de setores analisados caiu para 92. Essa redução teve como objetivo manter a confiabilidade dos resultados sem perdas de poder de estimação nos testes utilizados, especialmente para os de análise espacial, que podem demandar maiores graus de liberdade.

O uso de municípios para captar as externalidades marshallianas é mais apropriado neste estudo, pois a metodologia empregada não pode captar os efeitos do tamanho do mercado sobre as ligações interindustriais, como em Forni e Paba (2002). Dessa forma, como o foco do estudo é o setor industrial, que, em geral, atende mercados que ultrapassam os limites do município, os efeitos mencionados não podem ser grandes. Além disso, a variável que mede o emprego total local tende a capturar efeitos de demanda local, como observado em Combes (2000b) e discutido na revisão de literatura.

O método de estimação por máxima verossimilhança foi usado nos modelos espaciais com o fim de evitar problemas de endogeneidade decorrentes de simultaneidade entre a variável que mede crescimento do emprego total e a variável que mede a composição do emprego na região, tendo em vista que o crescimento do emprego total é, ao mesmo tempo, sensível à composição do emprego na área, e fator que afeta o nível e composição do emprego, conforme adverte Rosenthal e Strange (2004).

\subsection{Fonte e natureza dos dados}

O banco de dados utilizado no presente trabalho apresenta informações sobre o número de empregados e o número de estabelecimentos por setor de atividade, desagregadas no nível municipal. Tais informações são provenientes da Relação Anual de Informações Sociais (RAIS) e da RAIS-estabelecimento para o número de empresas em cada cidade, ambas as bases fornecidas pelo Ministério do Trabalho e Emprego (MTE, 2017), referentes ao período 1995-2014, agregadas segundo os setores de atividade

veis não revela possíveis problemas de multicolinearidade e pode ser requisitada aos autores. 
classificados a 2 e 3 dígitos, seguindo o código de Classificação Nacional de Atividades Econômicas (CNAE). ${ }^{2}$

As principais vantagens de utilizar dados de emprego para o estudo da relação entre externalidades e crescimento urbano estão relacionadas, principalmente no caso brasileiro, à disponibilidade de elevado nível de desagregação setorial e geográfica das informações com os dados da RAIS/ MTE (MTE, 2017). Estudo com similar grau de desagregação usando medidas de valor agregado, por exemplo, precisariam de tabulações especiais do Instituto Brasileiro de Geografia e Estatística (IBGE), as quais, em geral, são inviabilizadas por questões relacionadas à necessidade de sigilo das informações em nível muito desagregado, como setores e municípios, quando o número de empresas nestes é menor ou igual a três. Por outro lado, como desvantagem da RAIS, convém ressaltar que essa base engloba apenas o emprego formal.

Algumas limitações metodológicas podem ser apontadas e são decorrentes dos dados da RAIS, que apenas contempla os trabalhadores formalmente empregados do mercado de trabalho. Nesse sentido, a evidência indireta de transbordamento buscada aqui estaria vinculada aos dados do emprego formal em municípios brasileiros. Entretanto, como a indústria geral e de transformação possui melhor grau de cobertura dos trabalhadores de fato empregados nas localidades, o problema é, em parte, minimizado. $\bigcirc$ artigo limita-se a analisar setores cujo número de observações não fosse menor que 30 em nenhum dos anos, i.e., se em último caso o município tiver menos de 30 observações em cada ano será um total de 600 (20*30) informações no banco para esse setor. Contudo, a presença de tão poucas observações (não nulas) foi rara, em média o banco teve 479 observações por setor/ano e 9.588 de observações por setor, sendo que o setor com menos informações teve 916 informações no total e uma média de 46 informações por ano.

\section{Discussão dos Resultados}

A presente seção apresenta e discute os resultados da metodologia empregada, a qual permite identificar os setores receptores e os produtores de externalidades locais. As estimações foram feitas para cada um dos 92 2 A descrição completa dos setores encontra-se no Apêndice deste artigo (Quadro A1 e Quadro A2). 
setores, com desagregação a 3 dígitos pela CNAE, aplicando o método painel espacial em cada uma das equações setoriais. ${ }^{3}$

\subsection{Transbordamentos intersetoriais e intrassetoriais locais}

A Figura 1 apresenta a matriz construída para os coeficientes positivos dos índices de especialização de cada regressão, sejam não significativos ou significativos estatisticamente ('nos níveis de 1\%,5\% e 10\%). Nas linhas, estão os 92 setores industriais (a 3 dígitos $\mathrm{CNAE}$ ), e nas colunas estão os setores a 2 dígitos CNAE, agrupados de acordo com a intensidade tecnológica. Estes últimos representam uma fonte potencial (indireta) de transbordamento de tecnologia, enquanto os setores nas linhas representam os setores que absorvem tais transbordamentos. ${ }^{4}$ Pressupõe-se que os encadeamentos intersetoriais das relações de insumo-produto sejam as formas pelas quais as especializações a 2 dígitos CNAE influenciem os setores mais desagregados (a 3 dígitos CNAE).

$\mathrm{Na}$ Figura 1, cada linha representa um exercício econométrico, em que a variável dependente é o crescimento do emprego industrial a 3 dígitos de classificação CNAE, tendo com número de observações todos os municípios brasileiros. ${ }^{5}$ Cada célula traz os resultados dos coeficientes das variáveis de interesse, que são as especializações em grupos setoriais por intensidade tecnológica. Se colorida, a célula de cada linha indica que o coeficiente de especialização setorial $(\gamma)$ do modelo econométrico expresso pela equação (1) é significativo. A gradação de cores representa o nível de significância. Se preto, a significância é $1 \%$; se cinza escuro, $5 \%$; e se cinza, $10 \%$. Por outro lado, se for branca, a célula indica que o coeficiente daquela especialização industrial não é significativo na regressão.

3 Os subgrupos setoriais 111, 171, 231, 232, 233, 234, 243, 288, 297, 299, 301, 317, 318, 329, 333, 335, 339, 342 não puderam ser incluídos no estudo por causa do excessivo número de zeros, que impossibilitaram o cálculo da taxa de crescimento setorial.

4 As evidências de transbordamentos apresentadas aqui são indiretas porque não se baseiam nas medidas de "rent spillovers" (gastos de P\&D ponderados por matrizes de insumo-produto) ou "knowledge spillovers" (patentes) geralmente usadas na literatura (Hall; Mairesse; Mohnen, 2010).

5 Nem todos os municípios apresentaram informações sobre emprego na RAIS. Tabelas completas com as estimativas de cada variável do modelo, informações sobre p-valor, número de observações em cada setor, tipo de modelo espacial usado e número de vizinhos da matriz espacial podem ser requisitados aos autores. 
Considerando as variáveis $p v X_{-i t}$, do total de 460 células ( 92 setores por 5 variáveis de grupos setoriais), $31 \%$ não possuem significância estatística (cor branca). Entre as células significativas, $78 \%$ representam células com coeficientes $(\gamma)$ positivos, e $22 \%$, negativos. De modo geral, os coeficientes positivos e significativos (Figura 1) aparentam seguir um padrão não aleatório, ao contrário dos coeficientes negativos (Figura 2). Quando os coeficientes são positivos, isso significa que a especialização em indústrias a 2 dígitos, agrupadas por intensidade tecnológica, influencia positivamente o crescimento do emprego local a 3 dígitos. Por outro lado, quando os coeficientes são negativos, interpretação inversa pode ser realizada. A Figura 1 busca explanar o efeito tecnológico em de cada setor a 3 dígitos, considerando os resultados dos parâmetros $p v X_{-i t}$.

Figura 1 Matriz de transbordamentos intersetoriais e intrassetoriais positivos para a indústria brasileira. Período: 1995-2014

\begin{tabular}{|c|c|c|c|c|c|c|c|}
\hline 高 & $\overline{\underline{z}}$ & $\bar{z}$ & 立 & $\underline{m}$ & $\underset{z}{Z}$ & นุ & 总 \\
\hline 100 & & & & & & & IB \\
\hline 112 & & & & & & & IB \\
\hline 131 & & & & & & & IB \\
\hline 132 & & & & & & & IB \\
\hline 141 & & & & & & & IB \\
\hline 142 & & & & & & & IB \\
\hline 151 & & & & & & & B \\
\hline 152 & & & & & & & B \\
\hline 153 & & & & & & & B \\
\hline 154 & & & & & & & B \\
\hline 155 & & & & & & & B \\
\hline 156 & & & & & & & B \\
\hline 157 & & & & & & & B \\
\hline 158 & & & & & & & B \\
\hline 159 & & & & & & & $B$ \\
\hline 160 & & & & & & & B \\
\hline 172 & & & & & & & B \\
\hline 173 & & & & & & & $B$ \\
\hline 174 & & & & & & & B \\
\hline
\end{tabular}

\begin{tabular}{|c|c|c|c|c|c|c|}
\hline 㖜 & 音 & $\bar{z}$ & 䓀 & \begin{tabular}{l|l}
$\mathfrak{z}$ & $\mathrm{z}$ \\
\end{tabular} & 泾 & 总 \\
\hline 271 & & & & & & MB \\
\hline 272 & & & & & & MB \\
\hline 273 & & & & & & MB \\
\hline 274 & & & & & & MB \\
\hline 275 & & & & & & MB \\
\hline 281 & & & & & & $\mathrm{MB}$ \\
\hline 282 & & & & & & $\mathrm{MB}$ \\
\hline 283 & & & & & & MB \\
\hline 284 & & & & & & $\mathrm{MB}$ \\
\hline 289 & & & & & & $\mathrm{MB}$ \\
\hline 351 & & & & & & $\mathrm{MB}$ \\
\hline 241 & & & & & & MA \\
\hline 242 & & & & & & MA \\
\hline 244 & & & & & & MA \\
\hline 246 & & & & & & MA \\
\hline 247 & & & & & & MA \\
\hline 248 & & & & & & MA \\
\hline 249 & & & & & & $\mathrm{MA}$ \\
\hline 291 & & & & & & MA \\
\hline
\end{tabular}




\section{Figura 1 (continuação)}

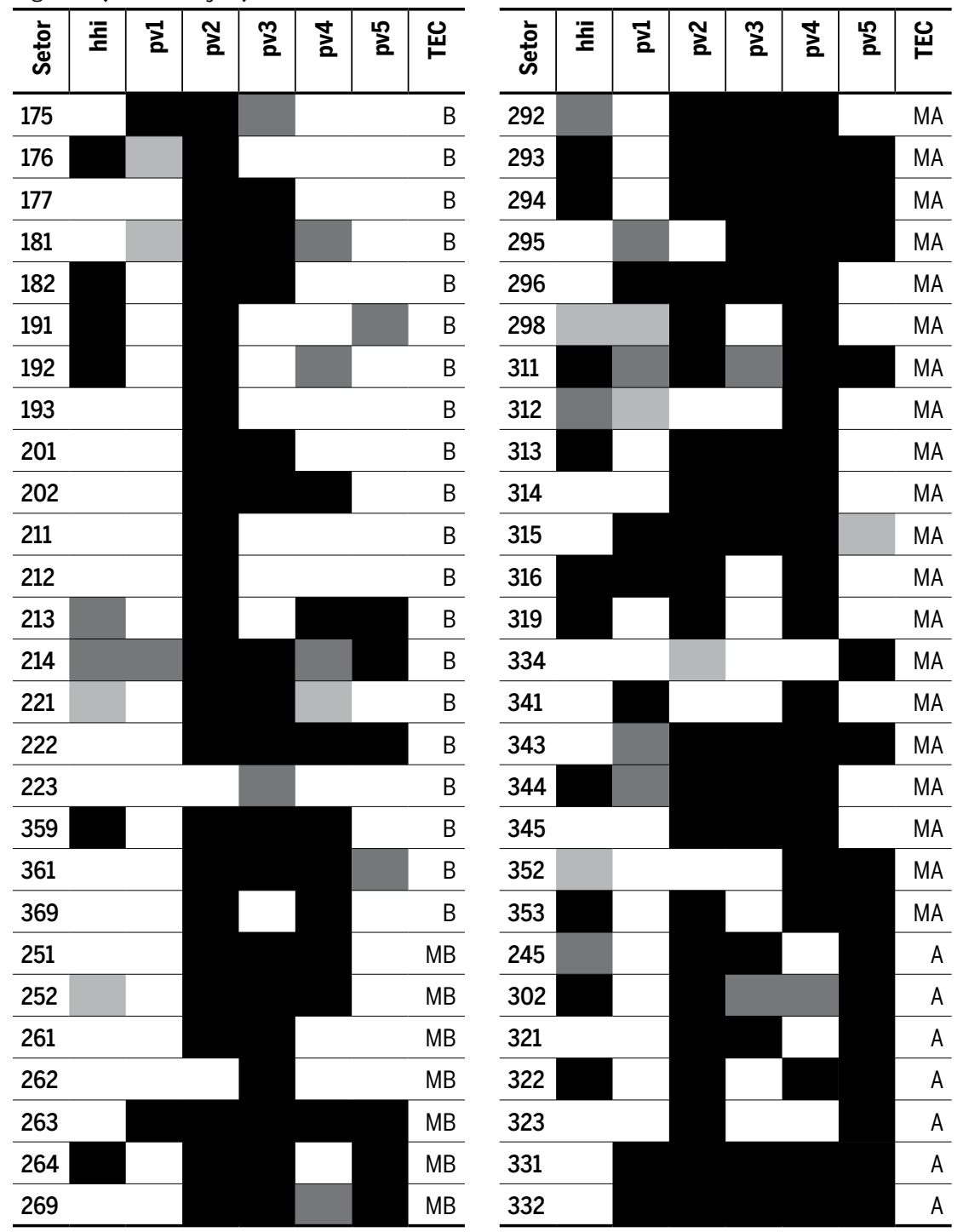

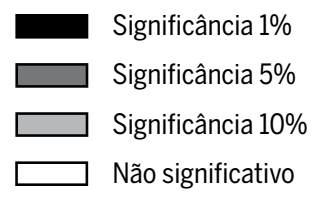

IB Ind. Extrativas - Baixa tecnologia

B Baixa tecnologia

MB Média-baixa tecnologia

$\square$ MA Média-alta tecnologia

A Alta tecnologia

Fonte: Elaboração própria. 
Figura 2 Matriz de transbordamentos intersetoriais e intrassetoriais negativos para a indústria brasileira. Período: 1995-2014

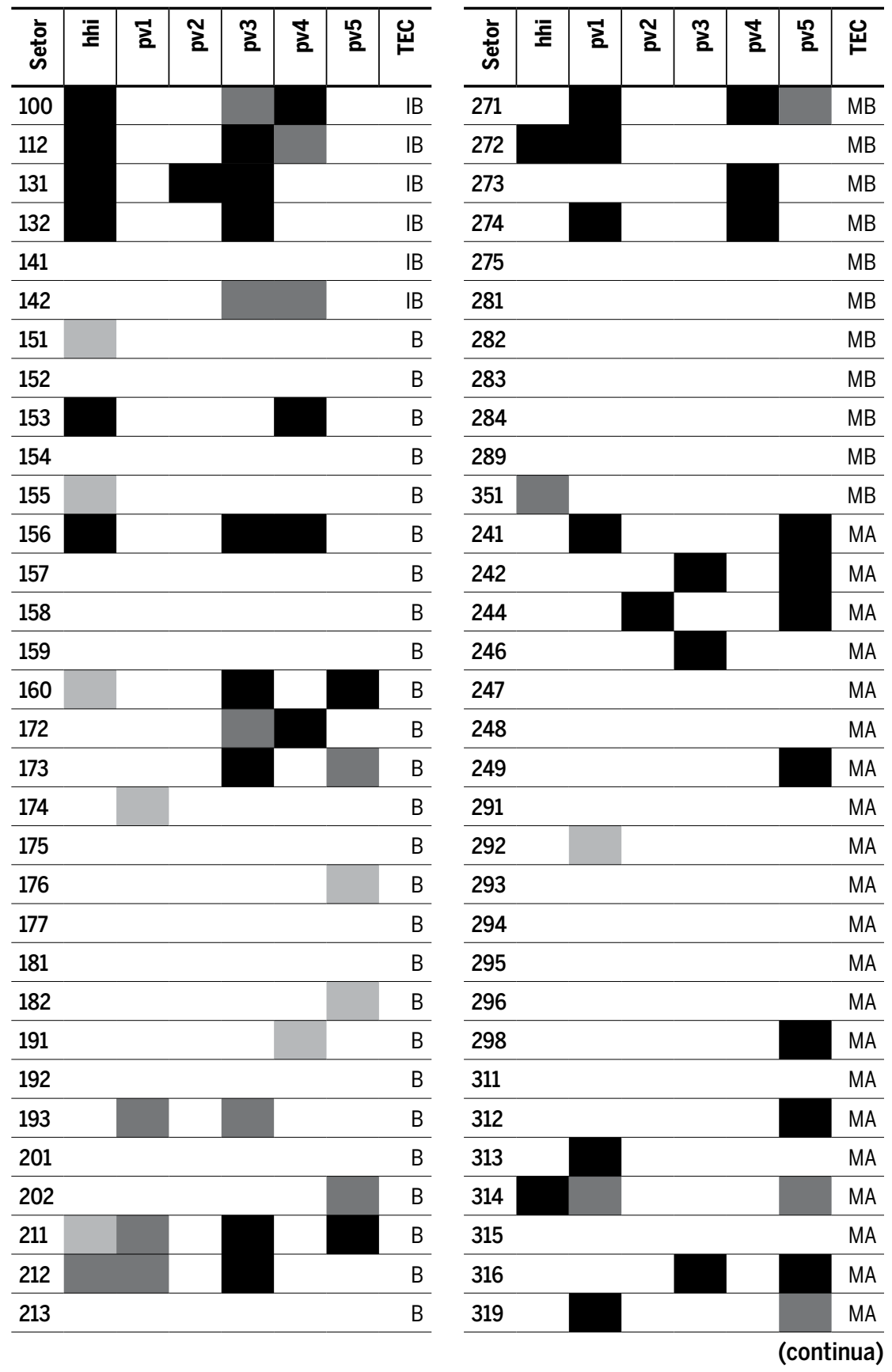


Figura 2 (continuação)

\begin{tabular}{|c|c|c|c|c|c|c|c|}
\hline $\begin{array}{l}\overline{\mathbf{a}} \\
\dot{\omega}\end{array}$ & 童 & $\bar{z}$ & $\mathfrak{z}$ & 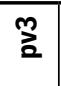 & 方 & $\vec{z}$ & 总 \\
\hline 214 & & & & & & & B \\
\hline 221 & & & & & & & B \\
\hline 222 & & & & & & & B \\
\hline 223 & & & & & & & B \\
\hline 359 & & & & & & & B \\
\hline 361 & & & & & & & B \\
\hline 369 & & & & & & & B \\
\hline 251 & & & & & & & $\mathrm{MB}$ \\
\hline 252 & & & & & & & $\mathrm{MB}$ \\
\hline 261 & & & & & & & $\mathrm{MB}$ \\
\hline 262 & & & & & & & $\mathrm{MB}$ \\
\hline 263 & & & & & & & $\mathrm{MB}$ \\
\hline 264 & & & & & & & $\mathrm{MB}$ \\
\hline 269 & & & & & & & $\mathrm{MB}$ \\
\hline
\end{tabular}

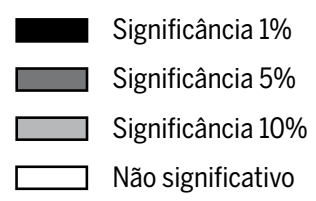

\begin{tabular}{|c|c|c|c|c|c|c|c|}
\hline 六 & 咅 & $\vec{z}$ & 喜 & 管 & 苂 & 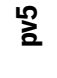 & 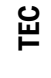 \\
\hline 334 & & & & & & & MA \\
\hline 341 & & & & & & & MA \\
\hline 343 & & & & & & & MA \\
\hline 344 & & & & & & & MA \\
\hline 345 & & & & & & & MA \\
\hline 352 & & & & & & & MA \\
\hline 353 & & & & & & & MA \\
\hline 245 & & & & & & & A \\
\hline 302 & & & & & & & A \\
\hline 321 & & & & & & & A \\
\hline 322 & & & & & & & A \\
\hline 323 & & & & & & & A \\
\hline 331 & & & & & & & A \\
\hline 332 & & & & & & & A \\
\hline
\end{tabular}

IB Ind. Extrativas - Baixa tecnologia

B Baixa tecnologia

MB Média-baixa tecnologia

MA Média-alta tecnologia

Alta tecnologia

Fonte: Elaboração própria.

Nos casos de coeficientes positivos (Figura 1), há grupos de setores que apresentam alta proporção de células significativas. Isso ocorre nos setores de baixa tecnologia (90\% dos casos), média-baixa (88\%) tecnologia e média-alta tecnologia (77\%). Desses, ampla maioria é composta por células positivas, sendo $86 \%, 68 \%$ e $61 \%$, respectivamente. Nos casos dos grupos setoriais relacionados a indústrias extrativas e setores de alta tecnologia, a maior parte das células é positiva, embora menor que nos três grupos descritos.

Ao se observar as origens dos transbordamentos (colunas), nota-se que as especializações em grupos de setores de baixa tecnologia geram estímulos em termos de crescimento do emprego em diversos outros setores, sejam de baixa, média-baixa, média-alta ou alta tecnologia. Por outro 
lado, setores de alta tecnologia geram, em termos de frequência, menor estímulo sobre crescimento do emprego, tendo em vista sua pouca dependência de trabalho e a complexidade de conhecimento necessário para seu funcionamento.

Observando-se a Figura 1 a partir das linhas (recepção dos estímulos), é possível notar a predominância de estímulos intragrupo de crescimento do emprego, no caso dos setores da indústria extrativa e de baixa tecnologia. Esses setores, desagregados a 3 dígitos, sempre são estimulados por especializações de mesma intensidade tecnológica e mais raramente por especializações em outros grupos. Notam-se clusters intragrupos em quase todos os subsetores analisados. Ou seja, isso significa dizer que um setor a 3 dígitos sempre é estimulado por especializações de mesma intensidade tecnológica.

Estímulos intersetoriais (intergrupos) ocorrem nos segmentos de maior intensidade tecnológica. Nos casos de subsetores de média-alta tecnologia, como grupos 291 a 296, 313 a 315, 343 a 345, esse padrão é mais claro. Nesses, especializações em baixa, média-baixa e alta tecnologia geram estímulos sobre tais setores, além da própria especialização em média-alta tecnologia (intragrupo). Clusters de grupos setoriais de diferentes intensidades tecnológicas indicam a importância de diversidade industrial do tecido urbano para fins de crescimento econômico. Tomando como exemplo o setor de calçados (grupo 193), de baixa tecnologia, em que se verifica, considerando-se os municípios brasileiros no período 1995-2014, que a variação do emprego é positivamente impactada pela especialização municipal em setores do grupo de baixa tecnologia, controlando-se outros fatores municipais que poderiam afetar o emprego no setor no período. De forma diferente, há subsetor de máquinas-ferramentas (grupo 294), considerado de média-alta tecnologia, cuja variação do emprego municipal, no período 1995-2014, pode ser explicada, em média, pelas especializações em diferentes grupos industriais, seja qual for a intensidade tecnológica.

Esses resultados não diferem daqueles existentes na literatura. Beaudry e Schiffauerova (2009) esperam que empresas de baixa intensidade em $\mathrm{P} \& \mathrm{D}$, mais frequentes em setores de baixa tecnologia, se beneficiam mais de localizações descentralizadas em regiões especializadas que oferecem vantagens de custos mais compatíveis com as externalidades do tipo MAR. Os autores detectam que tais externalidades MAR são levemente 
mais frequentes que as externalidades do tipo Jacobs. Estas externalidades de diversificação são mais favoráveis aos setores de alta tecnologia, conforme já haviam identificado Henderson, Kuncoro e Turner (1995), que fizeram regressões por setores segundo o nível tecnológico.

$\mathrm{Na}$ Figura 2, notam-se grupos setoriais com coeficientes negativos. Essas células possuem pequena frequência e mostram um padrão aparentemente aleatório, em contraste com a Figura 1. A maior proporção de células negativas ocorre nos setores de alta tecnologia, mas não ultrapassa $21 \%$ dos casos. Com base em Forni e Paba (2002), três explicações adicionais podem ser dadas a respeito dos resultados não significativos ou negativos mencionados: a) os setores possuem menores ligações interindustriais com o restante dos setores da economia; $b$ ) os setores podem ser pouco representados na estrutura industrial brasileira, o que dificulta a obtenção de coeficientes significativos, concluindo-se que, dessa forma, a especialização em tal setor não impacta o crescimento econômico municipal, em média, no Brasil; c) mesmo no caso de setores com maiores ligações médias intersetoriais, em termos de relações de insumo-produto, os setores podem ter poucas ligações interindustriais locais, com maiores ligações externas, de escalas geográficas maiores ou até mundiais; e d) substituição do fator trabalho por outros fatores de produção em razão de processos de restruturação industrial no longo período de tempo analisado.

As células não significativas são mais frequentes nas especializações em indústrias extrativas, de alta tecnologia e média-alta tecnologia, em que, respectivamente, 46, 39 e 25 setores a 3 dígitos não têm seu desempenho, em termos de emprego, influenciado por essas especializações. A razão disso pode ser a intensidade em capital dos setores e o próprio processo de desindustrialização do Brasil no período em análise, que se adéqua ao segundo ponto, apontado anteriormente por Forni e Paba (2002), sobre a pouca representatividade do setor na estrutura industrial do País. Segundo Brasil (2014), o processo de desindustrialização brasileiro foi mais intenso nos setores industriais de maior intensidade tecnológica, analisando-se o período de 1990-2012.

Outra variável de interesse, em face da discussão levantada na seção 2 deste artigo, é o índice de Herfindahl-Hirschman, que pode complementar as informações trazidas pela matriz de transbordamentos indiretos das Figuras 1 e 2 . Cerca de $73 \%$ dos 92 grupos industriais analisados possuem coeficiente significativo. Desses, $46 \%$ são positivos e $28 \%$ são negativos. 
Quanto maior (menor) o indicador, menor (maior) o grau de diversificação industrial do município. Analisando o indicador por setores segundo a intensidade tecnológica, nota-se que os coeficientes positivos são mais frequentes nos setores de baixa tecnologia. Ou seja, ambientes mais especializados, com menos setores diferentes, favorecem o crescimento do emprego nos setores de baixa tecnologia (grupos 157, 158, 159, 172, 174, 176, 182, 191, 192, 213, 214, 221 e 359). Por outro lado, não é raro encontrar casos em que ambientes diversificados sejam mais favoráveis ao emprego local mesmo no grupo de baixa tecnologia (grupos 153, 155, 156, 160, 211, 212, 222 e 361). Esses resultados revelam que o debate sobre a diversificação ou especialização do tecido industrial pode variar consideravelmente mesmo dentro de uma mesma intensidade tecnológica. No âmbito dos setores de média-alta e alta tecnologia é elevado o número de casos (15 setores) em que o coeficiente do indicador de Herfindahl-Hirschman foi também positivo, em relação aos casos de coeficientes negativos (6 setores). A interpretação é que ambientes urbanos especializados são mais favoráveis ao crescimento do emprego municipal nesses setores de alta e média-alta tecnologia. Tal resultado encontra suporte nos trabalhos de Catela, Gonçalves e Porcile (2010) e Gonçalves e Cunha (2015). Nesses, argumenta-se que as atividades industriais de maior conteúdo de conhecimento tecnológico precisam da especialização para atingir retornos crescentes e melhor desempenho urbano.

\subsection{Resultados das variáveis de controle}

A maioria das variáveis de controle do estudo foi significativa.

No caso da variação total do emprego no município $\left(\Delta n_{i t}\right)$ e quantidade total de empregados do município $\left(E_{i t}\right), 84 \%$ e $86 \%$ das regressões tiveram coeficientes significativos para essas variáveis, quase sempre positivos ( $80 \%$ e $85 \%$ dos casos respectivamente). A variação total do emprego no município $\left(\Delta n_{i t}\right)$ indicou que o desempenho setorial a 3 dígitos seguiu, em geral, a mesma tendência do desempenho geral da economia do município. Os coeficientes da quantidade total de empregados do município $\left(E_{i t}\right)$ foram negativamente associados às taxas de crescimento setoriais do emprego. Isso indica que a escala urbana está negativamente associada à variação setorial do emprego, sugerindo que municípios de maior porte econômico 
tiveram taxas setoriais de crescimento menores que os de menor porte, provavelmente por causa de externalidades negativas de urbanização. Esse fenômeno pode estar associado a um processo de descentralização do emprego no Brasil, em direção a municípios menores. Desde os anos de 1990 o Brasil passa por um processo de desconcentração regional do emprego e dos estabelecimentos industriais, com aumento de participação de regiões Norte, Nordeste e Centro-Oeste e também de microrregiões do interior de cada estado, conforme revela Saboia (2000), que analisou dados da RAIS, referentes ao período 1989/1997 para 155 microrregiões brasileiras. Como a evidência deste artigo se refere ao período 1995-2010, pode-se afirmar que, para todos os setores industriais brasileiros, essa tendência de desconcentração se manteve. ${ }^{6}$

Em relação à medida de capital humano $\left(\mathrm{CH}_{i t}\right)$, a proporção de coeficientes positivos é bem menor (49\% de $82 \%$ significativos). Os resultados revelam que o tipo de impacto é sensível ao setor a 3 dígitos considerado, havendo coeficientes positivos e negativos tanto para setores de maior intensidade tecnológica quanto para os de menor intensidade. Simon (1998) e Poelhekke (2013) encontram relação positiva entre emprego e capital humano, respectivamente, para os Estados Unidos e Alemanha. O argumento teórico estabelece que o estoque de indivíduos educados é precondição para absorver e criar conhecimento novo, que determina o crescimento econômico (Lucas, 1988). Em que pesem tais argumentos, não é incomum observar resultados negativos nas evidências empíricas. Paci e Usai (2006) encontram, por exemplo, evidências ambíguas em setores italianos. No caso brasileiro, como o número de coeficientes negativos é numeroso (33\% dos casos), nota-se que, em alguns setores, o estoque local de capital humano não é suficiente para criar os estímulos de crescimento de setores. A explicação desse resultado pode residir nos fatores que afetam negativamente a competitividade setorial, discutidos na seção 4.1, como a perda de importância de alguns setores industriais no Brasil ao longo das décadas de 1990 e 2000.

No caso do índice de competição local do setor $\left(C_{i h t}\right)$, a maior parte dos coeficientes são negativos ( $97 \%$ dos $100 \%$ significativos). Considerando que esse indicador também capta o inverso do tamanho médio das firmas por município, dada sua construção - número de estabelecimentos/núconsultar Azzoni (1986), Diniz (1993), Ferreira e Diniz (1995) e Azzoni (1997). 
mero de empregados - esse resultado pode implicar que o tamanho das firmas tem um papel determinante sobre o crescimento setorial. Em geral, a medida de competição setorial local $\left(C_{i h t}\right)$ revelou que, quanto maior o número de estabelecimentos por empregados, menor a variação setorial de emprego. O resultado é contrário à ideia de Porter (1990) de que um grande número de firmas de porte menor, competindo no mesmo território e no mesmo setor, pode induzir o crescimento econômico, favorecendo o argumento de Glaeser et al. (1992) de que monopólio local, ou menor competição de firmas por ideias, é melhor para o crescimento porque restringe o fluxo de ideias para terceiros, permitindo internalização de retornos do inovador.

A defasagem espacial da variável dependente $\left(W \Delta l_{i h t}\right)$ somente confirmou a existência de transbordamentos espaciais do crescimento do emprego urbano em $27 \%$ dos casos. No restante, essa variável não foi significativa. Isso significa que o crescimento do emprego de um município é positivamente correlacionado com o crescimento desse mesmo setor nos municípios vizinhos, embora isso ocorra em poucos casos. Esse resultado difere daqueles geralmente encontrados na literatura quando se utilizam variáveis de desempenho e unidades espaciais diferentes das usadas nesse artigo (Silveira Neto, 2001) ou em análises para municípios de unidades da federação específicas (Monasterio; Ávila, 2004; Ferrario et al., 2009). Esses trabalhos citados anteriormente são realizados sem a perspectiva setorial. É possível, porém, realizar uma comparação mais direta com o trabalho de Paci e Usai (2006). Neste, cross-sections são estimadas para 34 setores de 784 municipalidades italianas no período de 1991-1996. Os autores encontraram evidências de transbordamentos espaciais apenas para 9 setores industriais e de serviços. Desses, todos os setores da indústria de transformação eram de baixa intensidade tecnológica, como alimentos, bebidas e fumo, papel e móveis. Os resultados para a indústria brasileira encontrados no presente artigo ajudam a verificar em quais setores o crescimento ocorre em escala maior que a municipal, supondo que mecanismos de transmissão de estímulos entre os municípios, como os transbordamentos locais por intermédio de canais como mobilidade de pessoal e interação face a face com agentes econômicos, estejam operando em escala regional. 


\section{Conclusões}

A ideia central deste artigo foi verificar o impacto de especializações setoriais por nível de intensidade tecnológica na variação setorial do emprego por municípios brasileiros no período 1995-2014, fornecendo uma matriz de transbordamentos intersetoriais e intrassetoriais, positivos e negativos. Em termos metodológicos, o trabalho usou um painel espacial de dados, com a realização de 92 regressões setoriais a 3 dígitos (grupos industriais do IBGE). Com isso, foi possível controlar para os efeitos não observados municipais a influência da autocorrelação espacial nos resultados, além de construir uma especificação econométrica que considerou sugestões da literatura de incluir variáveis de controle importantes, como total do emprego da cidade, medida de capital humano local e medidas de diversificação setorial e especialização, permitindo, neste último tema, a coexistência das duas medidas representativas dessas características no território.

Os principais resultados podem ser assim resumidos:

a) Tanto a especialização quanto a diversidade setorial importam para o crescimento local, embora o conjunto de evidências seja multifacetado sob na pequena escala geográfica analisada. Especializações em grupos setoriais de baixa tecnologia geram transbordamentos para diversos outros grupos industriais, independentemente do nível de intensidade tecnológica. Os estímulos provenientes de setores de alta tecnologia são menos frequentes, embora também ocorram, dependendo do grupo industrial considerado. Por outro lado, em termos de recepção dos transbordamentos, setores de baixa tecnologia e indústria extrativa são sempre estimulados por especializações de mesma intensidade tecnológica. Diferentemente, os grupos de maior intensidade tecnológica recebem estímulos de diferentes especializações setoriais por nível de intensidade tecnológica. Os resultados dizem que os setores de maior intensidade tecnológica são favorecidos por externalidades de especialização (tipo MAR) no mesmo grupo de intensidade tecnológica a que pertencem e ainda de grupos provenientes de setores de diferentes intensidades tecnológicas. Essa diversidade de estímulos intersetoriais é também compatível com o argumento de Jacobs. O resultado é reforçado pelo indicador de Herfindahl-Hirschman, que sintetizou o perfil industrial do município. Os coeficientes dessa variável foram predominantemente positivos e 
significativos para os setores de maior intensidade tecnológica. Isso revela que tais setores precisam de economias locais, em média, mais especializadas para seu crescimento econômico. Como associações negativas entre o indicador acima e a variação de emprego também foram constatadas tanto para setores de maior quanto para os de menor intensidade tecnológica, nota-se que o debate diversificação/ especialização pode variar consideravelmente por grupo industrial.

b) Os casos de especializações com impacto negativo sobre o crescimento local foram menos frequentes e mostraram um padrão aleatório, diferente daqueles constatados acima. Razões vinculadas à redução ou menores ligações interindustriais, substituição de fator trabalho por outros fatores como resultado de transformações estruturais da economia brasileira e até mesmo redução na representatividade de tais setores na estrutura industrial brasileira podem explicar a associação negativa com o desempenho local e poderiam ser tema de extensões futuras do presente artigo.

c) Evidências de transbordamentos espaciais do crescimento do emprego local ocorreram somente em $27 \%$ das regressões setoriais. $\bigcirc$ resultado revela que os mecanismos de transmissão de estímulos de crescimento entre os municípios podem ser muito sensíveis ao tipo de indústria considerado e diferem das evidências agregadas em geral encontradas no Brasil sem distinguir o tipo de indústria.

Como este artigo mostra evidências mais refinadas sobre os tipos de externalidades que prevalecem sobre uma estrutura industrial muito desagregada na escala de munícipios brasileiros, os resultados podem, portanto, auxiliar no planejamento de políticas industriais, com foco local/regional, por grupos industriais da CNAE. Um mix de especialização e diversificação setoriais pode ser necessário para estímulos de diferentes grupos industriais, em particular de setores de maior intensidade tecnológica. Em geral, setores de baixa intensidade tecnológica precisam de especializações de mesma intensidade tecnológica. Associação positiva entre desempenho de um município e o de seus vizinhos ocorreu em alguns casos, o que requer que políticas públicas sejam pensadas para uma escala regional maior que a municipal.

Os resultados encontrados estão sujeitos a limitações decorrentes do uso dos dados de emprego. Logo, extensões futuras podem testar outros tipos de indicadores, como salários, valor agregado e produtividade a fim de originar testes de robustez necessários para esses resultados. 


\section{Referências}

AZZONI, C. R. Indústria e reversão da polarização no Brasil, São Paulo, IPE/USP, 1986.

AZZONI, C. R. Concentração regional e dispersão das rendas per capita estaduais: análise a partir das séries históricas estaduais de PIB, 1939-1995. Estudos Econômicos, v. 27, n. 3 p. 341-393, 1997.

BADIA, B. D.; FIGUEIRÊDO, L. Impacto das externalidades dinâmicas de escala sobre o crescimento do emprego industrial nas cidades brasileiras. In: XII ENCONTRO REGIONAL DE ECONOMIA, 2007, Fortaleza. Anais...

BEAUDRY, C.; SCHIFFAUEROVA, A. Who's Right, Marshall or Jacobs? The Localization Versus Urbanization Debate. Research Policy, v. 38, n. 2, p. 318-337, 2009.

BRASIL, L. A. Desindustrialização no Brasil nas décadas de 1990 e 2000: uma análise sob o prisma do nível de intensidade tecnológica da indústria. 2014. 96 p. Dissertação (Dissertação em Economia) - Universidade Federal do Rio Grande do Sul, Porto Alegre, 2014.

CATELA, E. Y. S.; GONÇALVES, F.; PORCILE, G. Brazilian Municipalities: Agglomeration Economies and Development Levels in 1997 and 2007. Cepal Review, n. 101, p. 141-156, 2010.

COMBES, P. P. Economic Structure and Local Growth: France, 1984-1993. Journal of Urban Economics, v. 47, n. 3, p. 329-355, 2000a.

COMBES, P. P. Marshall-Arrow-Romer Externalities and City Growth. Paris: Ecole Nationale des Ponts-et-Chaussées, p. 99-06, 2000b.

COMBES, P. P; MAGNAC, T.; ROBIN, J. M. The Dynamics of Local Employment in France. Journal of Urban Economics, v. 56, n. 2, p. 217-243, 2004.

DALBERTO, C. R.; STADUTO, J. A. R. Uma análise das economias de aglomeração e seus efeitos sobre os salários industriais brasileiros. Revista de Economia Contemporânea. Rio de Janeiro, v. 17, n. 3, p. 539-569, set.-dez./2013.

DINIZ, C. C. Desenvolvimento poligonal no Brasil: nem desconcentração nem contínua polarização, Nova Economia, v. 3, n. 1. Belo Horizonte: UFMG/FCE/DCE, 1993.

DURANTON, G; PUGA, D. Nursery Cities: Urban Diversity, Process Innovation, and the Life Cycle of Products. American Economic Review, v. 91, n. 5, p. 1454-1477, 2001.

FERRARIO et al. Uma análise espacial do crescimento econômico do estado do Paraná para os anos 2000 e 2004. Revista Brasileira de Estudos Regionais e Urbanos, 3 (1), p. 154-177, 2009.

FERREIRA, A. H. B.; DINIZ, C. C. Convergência entre as rendas per capita estaduais no Brasil, Revista de Economia Política, v. 11, n. 4, 1995.

FOCHEZATTO, A; VALENTINI, P. J. Economias de aglomeração e crescimento econômico regional: um estudo aplicado ao Rio Grande do Sul usando um modelo econométrico com dados de painel. Economia, Brasília, DF, v. 11, n. 4, p. 243-266, dez. 2010.

FORNI, M.; PABA, S. Spillovers and the Growth of Local Industries. The Journal of Industrial Economics, v. 50, n. 2, p. 151-171, 2002.

GALINARI, R. et al. O efeito das economias de aglomeração sobre os salários industriais: uma aplicação ao caso brasileiro. Revista de Economia Contemporânea, v. 11, p. 391-420, 2007. 
GLAESER, E. L. et al. Growth in Cities. The Journal of Political Economy, v. 100, n. 6, Centennial Issue (Dec., 1992), pp. 1126-1152.

GONÇALVES, E.; ALMEIDA, E. S. Innovation and Spatial Knowledge Spillovers: Evidence from Brazilian Patent Data. Regional Studies, v. 43, n. 4, p. 513-528, 2009.

GONÇALVES, E.; CUNHA, R. Intensidade tecnológica industrial, externalidades locais e produtividade urbana: uma análise por cidades brasileiras no período 2000-2010. Revista Econômica do Nordeste, v. 46, p. 41-60, 2015.

HALL, B. H.; MAIRESSE, J.; MOHNEN, P. Measuring the Returns to R\&D. In: HALL; B. H.; ROSENBERG, N. (Ed.). Handbook of Economics of Innovation. Elsevier, 2010, cap. 24.

HENDERSON, J. V. Externalities and Industrial Development. Journal of Urban Economics, v. 42, n. 3, p. 449-470, 1997.

HENDERSON, V.; KUNCORO, A.; TURNER, M. Industrial Development in Cities. Journal of Political Economy, 103, pp. 1067-1090, 1995.

JACOBS, J. The Economy of Cities. Random House, New York, 1969.

KOO, J. Agglomeration and Spillovers in a Simultaneous Framework. The Annals of Regional Science, v. 39, n. 1, p. 35-47, 2005.

LU, Y. et al. City-Industry Growth in China. China Economic Review, v. 27, p. 135-147, 2013.

LUCAS, R. E. On the Mechanics of Economic Development. Journal of Monetary Economics, v. 22, p. 3-42, 1988.

MARSHALL, A. Princípios de economia. São Paulo: Abril Cultural, 1982.

MINISTÉRIO DO TRABALHO E EMPREGO (MTE). RAIS - Relação Anual de Informações Sociais. Disponível em: <www.mte.gov.br>. Acesso em: jun. 2017.

MONASTERIO, L. M.; ÁVILA, R. P. Uma análise espacial do crescimento econômico do Rio Grande do Sul (1939-2001). Economia, v. 5 (2), 269-296, 2004.

MONTENEGRO, R. L. G.; GONÇALVES, E.; ALMEIDA, E. S. Dinâmica espacial e temporal da inovação no Estado de São Paulo: uma análise das externalidades de diversificação e especialização. Estudos Econômicos, v. 41, p. 1-34, 2011.

PACI, R.; USAI, S. The Role of Specialisation and Diversity Externalities in the Agglomeration of Innovative Activities. Rivista Italiana degli Economisti, v. 2, n. 2, p. 237-268, 2000.

PACI, R., USAI, S. Spatial Externalities and local Employment Dynamics. In: VERTOVA, G. The Changing Economic Geography of Globalization: Reinventing Space. London/New York: Routledge, 2006.

POELHEKKE, S. Human Capital and Employment Growth in German Metropolitan Areas: New Evidence. Regional Studies, v. 47, n. 2, p. 245-263, 2013.

PORTER, M. E. The Competitive Advantage of Nations. London: Macmillan, 1990.

ROMER, P. Increasing Returns and Long-Run Growth. Journal of Political Economy, Chicago, v. 94 , p. $1002-1037,1986$

ROSENTHAL, S. S.; STRANGE, W. C. Evidence on the Nature and Sources Of Agglomeration Economies. In: HENDERSON, V.; THISSE, J. F. (Ed.). Handbook of Urban and Regional Economics, v. 4, n. 4. Elsevier-North Holland, Amsterdam, 2004. 
SABOIA, J. Desconcentração industrial no Brasil nos anos 90: um enfoque regional. Pesquisa e Planejamento Econômico, v. 30, n. 1, p. 69-116, 2000.

SILVA, M. V. B.; SILVEIRA NETO, R. M. Crescimento do emprego industrial no Brasil e geografia econômica: evidências para o período pós-real. Economia, Brasília, DF, v. 8, n. 2, p. 269-288, maio/ago. 2007.

SILVEIRA NETO, R. Crescimento e spillovers: a localização importa? Evidências para os estados brasileiros. Revista Econômica do Nordeste, v. 32, p. 524-545, 2001.

SIMON, C. J. Human Capital and Metropolitan Employment Growth. Journal of Urban Economics, v. 43, n. 2, p. 223-243, 1998.

\section{Sobre os autores}

Eduardo Gonçalves-eduardo.goncalves@ufjf.edu.br

Universidade Federal de Juiz de Fora, Juiz de Fora, Minas Gerais, Brasil. ORCID: https://orcid.org/0000-0003-2017-3454.

Raphael de Freitas Saldanha-rfsaldanha@gmail.com

Universidade Federal de Juiz de Fora, Juiz de Fora, Minas Gerais, Brasil. ORCID: https://orcid.org/0000-0003-0652-8466.

Eduardo Almeida - eduardo.almeida@ufff.edu.br

Universidade Federal de Juiz de Fora, Juiz de Fora, Minas Gerais, Brasil. ORCID: https://orcid.org/0000-0003-0045-1672.

André Suriane da Silva-andresuriane@gmail.com

Universidade Federal de Juiz de Fora, Juiz de Fora, Minas Gerais, Brasil.

ORCID: https://orcid.org/0000-0002-5942-3257.

Os autores Eduardo Gonçalves e Eduardo Almeida gostariam de agradecer o financiamento da Fundação de Amparo à Pesquisa do Estado de Minas Gerais (Fapemig), ao Conselho Nacional de Desenvolvimento Científico e Tecnológico (CNPq) e à Universidade Federal de Juiz de Fora.

\section{Sobre 0 artigo}

Recebido em 12 de março de 2016. Aprovado em 12 de novembro de 2017. 


\section{APÊNDICE}

\section{Quadro A1 Descrição dos setores a 2 dígitos (divisões) CNAE 1.0/CNAE-FISCAL 1.1}

\begin{tabular}{|c|c|}
\hline Divisão & Descrição \\
\hline 10 & Extração de carvão mineral \\
\hline 11 & Extração de petróleo e serviços relacionados \\
\hline 12 & Extração de minerais metálicos \\
\hline 13 & Extração de minerais não metálicos \\
\hline 15 & Produtos alimentícios e bebidas \\
\hline 16 & Produtos do fumo \\
\hline 17 & Produtos têxteis \\
\hline 18 & Artigos do vestuário e acessórios \\
\hline 19 & Preparação de couros e Fabricação de artefatos de couro, artigos de viagem e calçados \\
\hline 20 & Produtos de madeira \\
\hline 21 & Celulose, papel e produtos de papel \\
\hline 22 & Edição, impressão e reprodução de gravações \\
\hline 23 & Coque, refino de petróleo, elaboração de combustíveis nucleares e produção de álcool \\
\hline 24 & Produtos químicos \\
\hline 25 & Artigos de borracha e de material plástico \\
\hline 26 & Produtos de minerais não metálicos \\
\hline 27 & Metalurgia básica \\
\hline 28 & Produtos de metal - exclusive máquinas e equipamentos \\
\hline 29 & Máquinas e equipamentos \\
\hline 30 & Máquinas para escritório e equipamentos de informática \\
\hline 31 & Máquinas, aparelhos e materiais elétricos \\
\hline 32 & Material eletrônico e de aparelhos e equipamentos de comunicações \\
\hline 33 & $\begin{array}{l}\text { Equipamentos de instrumentação médico-hospitalares, instrumentos de precisão e } \\
\text { ópticos, equipamentos para automação industrial, cronômetros e relógios }\end{array}$ \\
\hline 34 & Montagem de veículos automotores, reboques e carrocerias \\
\hline 35 & Outros equipamentos de transporte \\
\hline 36 & Móveis e indústrias diversas \\
\hline
\end{tabular}

Fonte: Adaptado de IBGE. 
Quadro A2 Descrição dos setores a 3 dígitos (grupos) CNAE 1.0/CNAE-Fiscal 1.1

\begin{tabular}{|c|c|}
\hline Divisão & Descrição \\
\hline 100 & Extração de carvão mineral \\
\hline 111 & Extração de petróleo e gás natural \\
\hline 112 & $\begin{array}{l}\text { Ativ. de serv. relacionados com a extração de petróleo e gás } \\
\text { (exceto a prospecção realizada por terceiros) }\end{array}$ \\
\hline 131 & Extração de minério de ferro \\
\hline 132 & Extração de minerais metálicos não ferrosos \\
\hline 141 & Extração de pedra, areia e argila \\
\hline 142 & Extração de outros minerais não metálicos \\
\hline 151 & Abate e preparação de produtos de carne e de pescado \\
\hline 152 & $\begin{array}{l}\text { Processamento, preservação e produção de conservas de frutas, legumes e outros } \\
\text { vegetais }\end{array}$ \\
\hline 153 & Óleos e gorduras vegetais e animais \\
\hline 154 & Laticínios \\
\hline 155 & Moagem, fabricação de produtos amiláceos e de rações balanceadas para animais \\
\hline 156 & Fabricação e refino de açúcar \\
\hline 157 & Torrefação e moagem de café \\
\hline 158 & Outros produtos alimentícios \\
\hline 159 & Bebidas \\
\hline 160 & Produtos do fumo \\
\hline 172 & Fiação \\
\hline 173 & Tecelagem - inclusive fiação e tecelagem \\
\hline 174 & Artefatos têxteis incluindo tecelagem \\
\hline 175 & Acabamentos em fios, tecidos e artigos têxteis, por terceiros \\
\hline 176 & Artefatos têxteis a partir de tecidos - exclusive vestuário \\
\hline 177 & Tecidos e artigos de malha \\
\hline 181 & Confecção de artigos do vestuário \\
\hline 182 & Acessórios do vestuário e de segurança profissional \\
\hline 191 & Curtimento e outras preparações de couro \\
\hline 192 & Artigos para viagem e de artefatos diversos de couros \\
\hline 193 & Calçados \\
\hline 201 & Desdobramento de madeira \\
\hline 202 & Produtos de madeira, cortiça e material trancado - exceto móveis \\
\hline 211 & Celulose e outras pastas para a fabricação de papel \\
\hline 212 & Papel, papelão liso, cartolina e cartão \\
\hline
\end{tabular}


Quadro A2 (continuação)

\begin{tabular}{|c|c|}
\hline Divisão & Descrição \\
\hline 213 & Embalagens de papel ou papelão \\
\hline 214 & Artefatos diversos de papel, papelão, cartolina e cartão \\
\hline 221 & Edição e impressão \\
\hline 222 & Impressão e serviços conexos para terceiros \\
\hline 223 & Reprodução de materiais gravados \\
\hline 231 & Coquerias \\
\hline 232 & Produtos derivados do petróleo \\
\hline 233 & Combustíveis nucleares \\
\hline 241 & Produtos químicos inorgânicos \\
\hline 242 & Produtos químicos orgânicos \\
\hline 243 & Resinas e elastômeros \\
\hline 244 & Fibras, fios, cabos e filamentos contínuos artificiais e sintéticos \\
\hline 245 & Produtos farmacêuticos \\
\hline 246 & Defensivos agrícolas \\
\hline 247 & Sabões, detergentes, produtos de limpeza e artigos de per... \\
\hline 248 & Tintas, vernizes, esmaltes, lacas e produtos afins \\
\hline 249 & Produtos e preparados químicos diversos \\
\hline 251 & Artigos de borracha \\
\hline 252 & Produtos de plástico \\
\hline 261 & Vidro e produtos de vidro \\
\hline 262 & Cimento \\
\hline 263 & Artefatos de concreto, cimento, fibrocimento e gesso \\
\hline 264 & Produtos cerâmicos \\
\hline 269 & Aparelhamento de pedras e fabricação de cal e de outros produtos... \\
\hline 271 & Ferro-gusa e de ferroligas \\
\hline 272 & Siderurgia \\
\hline 273 & Tubos - exceto em siderúrgicas \\
\hline 274 & Metalurgia de metais não ferrosos \\
\hline 275 & Fundição \\
\hline 281 & Estruturas metálicas e obras de caldeiraria pesada \\
\hline 282 & Tanques, caldeiras e reservatórios metálicos \\
\hline 283 & Forjaria, estamparia, metalurgia do pó e serv. de tratamento de met... \\
\hline 284 & Artigos de cutelaria, de serralheria e de ferramentas man... \\
\hline 288 & Manutenção e reparação de tanques, caldeiras e reservatórios metálicos \\
\hline
\end{tabular}


Quadro A2 (continuação)

\begin{tabular}{|c|c|}
\hline Divisão & Descrição \\
\hline 289 & Produtos diversos de metal \\
\hline 291 & Motores, bombas, compressores e equipamentos de transmissão \\
\hline 292 & Máquinas e equipamentos de uso geral \\
\hline 293 & Máquinas e equipamentos para agricultura e avicultura \\
\hline 294 & Máquinas-ferramentas \\
\hline 295 & Máquinas e equip. de uso na extr. mineral e construção \\
\hline 296 & Outras máquinas e equipamentos de uso especifico \\
\hline 297 & Armas, munições e equipamentos militares \\
\hline 298 & Eletrodomésticos \\
\hline 299 & Manutenção e reparação de máquinas e equipamentos industriais \\
\hline 301 & Máquinas para escritório \\
\hline 302 & Fab. de máquinas e equipamentos de sistemas eletrônicos para processamento de dados \\
\hline 311 & Motores elétricos, geradores e transformadores \\
\hline 312 & Equipamentos para distribuição e controle de energia elétrica \\
\hline 313 & Fios, cabos e condutores elétricos isolados \\
\hline 314 & Pilhas, baterias e acumuladores elétricos \\
\hline 315 & Lâmpadas e equipamentos de iluminação \\
\hline 316 & Material elétrico para veículos - exclusive baterias \\
\hline 318 & Manutenção e reparação de máquinas, aparelhos e materiais elétricos \\
\hline 319 & Outros equipamentos e aparelhos elétricos \\
\hline 321 & Material eletrônico básico \\
\hline 322 & $\begin{array}{l}\text { Aparelhos e equipamentos de telefonia e radiotelefonia e de transmissores de televisão } \\
\text { e rádio }\end{array}$ \\
\hline 323 & $\begin{array}{l}\text { Aparelhos receptores de rádio e televisão e de reprodução, gravação ou amplificação de } \\
\text { som e vídeo }\end{array}$ \\
\hline 331 & $\begin{array}{l}\text { Aparelhos e instrumentos para usos médico-hospitalares, odontológicos e de laborató- } \\
\text { rios e aparelhos ortopédicos }\end{array}$ \\
\hline 332 & Aparelhos e instrumentos de medida, teste e controle \\
\hline 334 & Aparelhos e instrumentos óticos, fotográficos e cinematográficos \\
\hline 335 & Cronômetros e relógios \\
\hline 339 & $\begin{array}{l}\text { Manutenção e reparação de equipamentos médico-hospitalares, instrumentos de preci- } \\
\text { são e óticos e equipamentos para automação industrial }\end{array}$ \\
\hline 341 & Automóveis, caminhonetas e utilitários \\
\hline 342 & Caminhões e ônibus \\
\hline
\end{tabular}


Quadro A2 (continuação)

\begin{tabular}{l|l}
\hline Divisão & Descrição \\
\hline 343 & Cabines, carrocerias e reboques \\
\hline 344 & Peças e acessórios para veículos automotores \\
\hline 345 & Recondicionamento ou recuperação de motores para veículos automotores \\
\hline 351 & Construção e reparação de embarcações \\
\hline 352 & Construção, montagem e reparação de veículos ferroviários \\
\hline 353 & Construção, montagem e reparação de aeronaves \\
\hline 359 & Outros equipamentos de transporte \\
\hline 361 & Artigos do mobiliário \\
\hline 369 & Produtos diversos \\
\hline
\end{tabular}

Fonte: Adaptado de IBGE.

Baseado na estrutura de classificação da Classificação Nacional de Atividades Econômicas (CNAE), versão 1.0 e CNAE-Fiscal 1.1. 